\title{
GENERATION OF SILVER NANOPARTICLES BY THE PIN-HOLE DC PLASMA SOURCE WITH AND WITHOUT GAS BUBBLING
}

\author{
Z. KozÁková*, F. KrČma, L. Čechová, S. Simić, L. DoskočIl \\ Faculty of Chemistry, Brno University of Technology, Purkyňova 118, 61200 Brno, Czech Republic \\ * kozakova@fch.vut.cz
}

\begin{abstract}
Silver nanoparticles were produced using the pin-hole discharge generated by dc nonpulsing high voltage directly in silver nitrate solutions. Sodium nitrate was alternatively added to increase solution conductivity and decrease input energy for the discharge breakdown. Argon or oxygen was bubbled through the discharge region. Comparative experiments were evaluated by UV-VIS spectrometry. Formation of silver nanoparticles with the average size of $100 \mathrm{~nm}$ was confirmed by SEM/EDS analysis.
\end{abstract}

Keywords: plasma in liquids, pin-hole discharges, silver nanoparticles, silver nitrate, gas bubbling, SEM/EDS analysis.

\section{Introduction}

Particles with specific size in the range between $10^{-9}$ to $10^{-7} \mathrm{~m}$ in diameter are called nanoparticles (NPs) $[1,2]$. Materials in these dimensions have different properties than the bulk material and this is one of many reasons why the contemporary worldwide research is focused just on nanoparticles. Properties of NPs are dependent on their composition, size, shape, and other parameters like internal structure. The metallic nanomaterials (including the alloyed ones) $[3,4]$ can be synthetized as well as semiconductors [5] or organics (like graphene [6] or polymers [7]). Because of NPs unique properties, these materials are used in many application fields such as photovoltaics [8], electronics [9], diagnostics sensors [10], conductive inks [11], nanocomposites [12,13], surface treatment [14], etc. A specific application field is in the medical therapy $[15,16]$ and health care. Thanks to their antibacterial effects, NPs are incorporated in biomedical devices, textiles, footwear or wound protections.

One of the means how to prepare NPs is the direct application of electrical discharge in liquids. Formed plasma channels are usually propagating through the liquid phase by the discharge itself with simultaneous discharge radiation. The discharge usually propagates from one electrode into the liquid and thus, the second electrode is formed by the gas (plasma) liquid surface. An advantage of plasma systems generated inside the liquid is the possibility to control the gaseous phase (even if some gas is bubbling into the system). Further, the whole system is efficiently self-mixed which helps to uniform the size of formed NPs. The precursors can be dissolved in the liquid or can be dissolved/sputtered from the electrode materials.

This paper deals with synthesis of silver nanoparticles by a special pin-hole electrode system using DC high voltage up to $1 \mathrm{kV}$ which gave the mean power up to $150 \mathrm{~W}$. Silver nitrate solutions were used as the precursor. Additionally, two gases (argon and oxygen) were bubbled through the main electrode into the plasma region in order to study effects of their flow rate on the NPs production.

\section{Experimental setup}

The electrode system of plasma reactor (Figure 1) consisted of two electrodes [17]. The main jet electrode was constructed by a tungsten wire (diameter of $1.0 \mathrm{~mm}$ ) which was inserted into a dielectric cylindrical rod made of Macor ceramics with outer diameter of $10 \mathrm{~mm}$ and with one conical end. An orifice with the diameter of $1.2 \mathrm{~mm}$ was made in the ceramics along its longitudinal axis. A small gap of $1 \mathrm{~mm}$ was kept between the end of the wire electrode and the end of the dielectric rod. This configuration substantially increased electric field intensity and thus it allowed plasma ignition at relatively low applied voltage. An outer glass tube served as a holder and as a gas inlet. The second electrode was a planar plate made of platinum with dimensions of $20 \times 100 \mathrm{~mm}^{2}$. Both electrodes were immersed in a vessel containing $500 \mathrm{ml}$ of silver nitrate solution. $\mathrm{AgNO}_{3}$ concentration varied from 25 to $150 \mathrm{mg} \mathrm{l}^{-1}$ (initial conductivity of $\left.20-100 \mu \mathrm{S} \mathrm{cm} \mathrm{cm}^{-1}\right)$. In some experiments, sodium nitrate $\left(100\right.$ or $\left.200 \mathrm{mgl}^{-1}\right)$ was added in order to increase initial conductivity up to $300 \mathrm{\mu S} \mathrm{cm} \mathrm{cm}^{-1}$ and to decrease the input energy for the discharge breakdown. Influence of gas bubbling through the discharge region on the particle formation was studied in two gases (argon and oxygen) with flow rates in the range of $10-50 \mathrm{ml} \mathrm{min}^{-1}$.

The system was supplied by dc non-pulsing high voltage up to $1 \mathrm{kV}$ with the negative polarity on the main electrode. The discharge itself showed selfpulsing operation [17] giving the mean input power up to $150 \mathrm{~W}$.

Treated solutions were sampled every 30 seconds during the discharge operation for UV-VIS spectrom- 


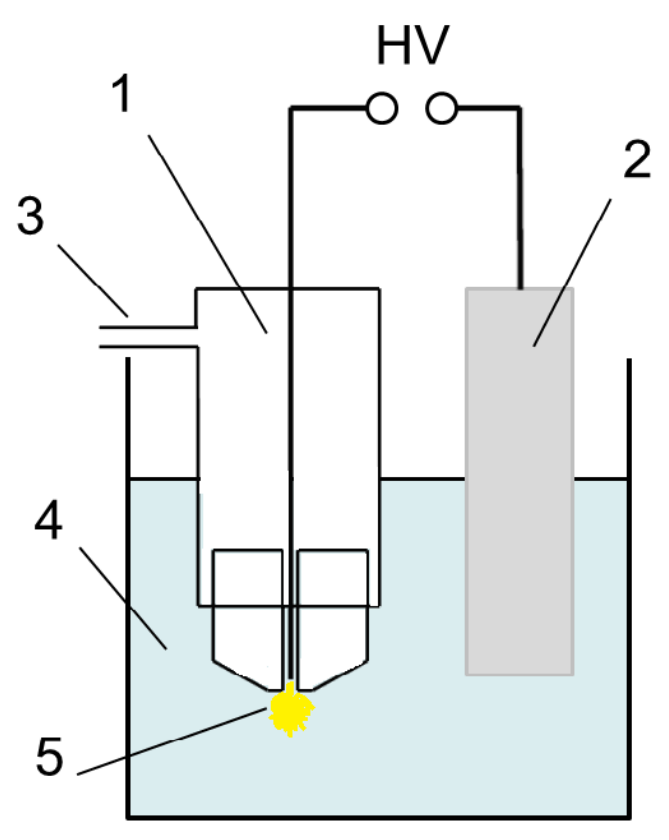

Figure 1. Simplified scheme of plasma reactor: 1 jet electrode, 2 - counter electrode, 3 - gas inlet, 4 glass vessel with $\mathrm{AgNO}_{3}$ solution, 5 - active plasma region.

etry. Absorption spectra of sample solutions were recorded by the Helios Omega spectrometer in the range of $300-600 \mathrm{~nm}$. Final solutions after the total two minute treatment were prepared for SEM and EDS analyses. These samples were obtained by evaporation of 20 drops of the final solutions on special aluminium holders. Detailed photos of formed nanoparticles were taken by the scanning electron microscope JEOL JSM-7600F with magnification of $3000 \mathrm{x}$ and $50000 \mathrm{x}$, respectively. Material composition of nanoparticles was confirmed by the electron disperse spectrometer with the accelerating voltage of $10 \mathrm{kV}$.

\section{Results}

Formation of silver nanoparticles by the pin-hole discharge in silver nitrate solution was confirmed by SEM/EDS analysis. Figure 2(a) presents photographs in the smaller magnification of 3000x where Ag NPs are visible as tiny dots spread among larger aggregates. These larger structures might have been formed both during the discharge treatment as well as the sample preparation (evaporation) for the SEM analysis. In the higher magnification of $50000 \mathrm{x}$ (Figure 2(b)), separate $\mathrm{Ag}$ NPs with dimensions around $100 \mathrm{~nm}$ are well visible. Material of formed particles detected by EDS analysis was composed mostly of silver with some traces of aluminium (from the holder) and carbon (human contamination).

Typical absorption spectra of $\mathrm{AgNO}_{3}$ solution recorded during the discharge treatment without any gas bubbling are shown in Figure 3. The initial sample of pure $\mathrm{AgNO}_{3}$ solution does not absorb in the studied wavelength range around $400 \mathrm{~nm}$ which is the typical wavelength of silver nanoparticles absorption reported in the literature [18]. Due to the dc discharge operation, silver nanoparticles are formed in the plasma region surrounding the main jet electrode (cathode). Further, they are spread into the bulk solution by the discharge self-mixing properties. Thus, the absorbance of colloidal silver solution is increased linearly during the discharge treatment with the maximal absorption at $410 \mathrm{~nm}$.

Influence of initial $\mathrm{AgNO}_{3}$ concentration in the solution on formation of Ag NPs was studied in the concentration range of $25-150 \mathrm{mg} \mathrm{l}^{-1}$. No gas was added in this series of experiments. According to the final absorbance of silver particles at $410 \mathrm{~nm}$ (Figure 4), it is obvious that formation of Ag NPs after two minute discharge treatment is increased up to the initial concentration of $100 \mathrm{mg} \mathrm{l}^{-1}$. However, it is substantially decreased by higher concentration. We assume that with the increasing silver nitrate concentration, higher amount of silver particles is formed but they easily aggregate into larger structures. These heavier structures come faster under sedimentation and thus absorption of the final solution is decreased. Therefore, it is important to adjust the optimal initial concentration of the precursor $\mathrm{AgNO}_{3}$ (until $100 \mathrm{mgl}^{-1}$ ) in order to produce homogeneous solution with silver nanoparticles.

As the initial conductivity of the primary silver nitrate solution reached only few tens of $\mu \mathrm{S} \mathrm{cm}^{-1}$ depending on the initial concentration, sodium nitrate of two concentrations was added in order to increase the initial conductivity. It is already known [19] that ignition as well as operation of dc discharges is strongly dependent on initial conductivity. Therefore, by the addition of sodium nitrate (concentration of 100 or $200 \mathrm{mg} \mathrm{l}^{-1}$ ) we have reached a stable discharge operation even at $40 \mathrm{~W}$ instead of $100 \mathrm{~W}$. However, final production of Ag NPs measured by the absorption at $410 \mathrm{~nm}$ seems much lower with the $\mathrm{NaNO}_{3}$ addition (Figure 5).

Influence of additional gas bubbled through the discharge region on $\mathrm{Ag}$ NPs formation was studied for two gasses. Argon was selected as an inert representative and oxygen as a reactive gas. We had supposed that by the ionisation of argon, the transfer of plasma energy for reduction of silver ions to nanoparticles should have been more effective. However, the experimental effect was totally opposite (Figure 6). Maximal absorbance at $410 \mathrm{~nm}$ recorded for final $\mathrm{AgNO}_{3}$ solutions after two minute discharge operation significantly decreases with the increasing flow rate of argon. The problem is probably in the formation of huge bubbles which interrupt the reduction process. The same trend was observed also for oxygen addition (Figure 7) where this suppressing effect was even stronger. The lower 


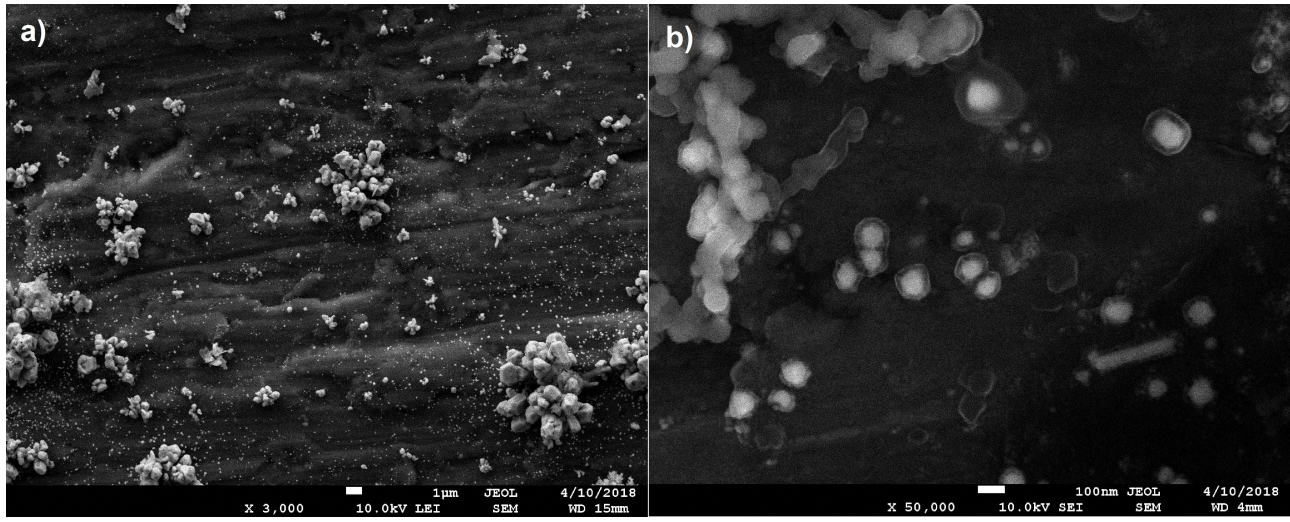

Figure 2. SEM photographs of silver nanoparticles formed after two minute discharge treatment (100 W) in $\mathrm{AgNO}_{3}$ solution (100 mgl $\mathrm{l}^{-1}$ ); magnification: a) 3000x, b) $50000 x$.

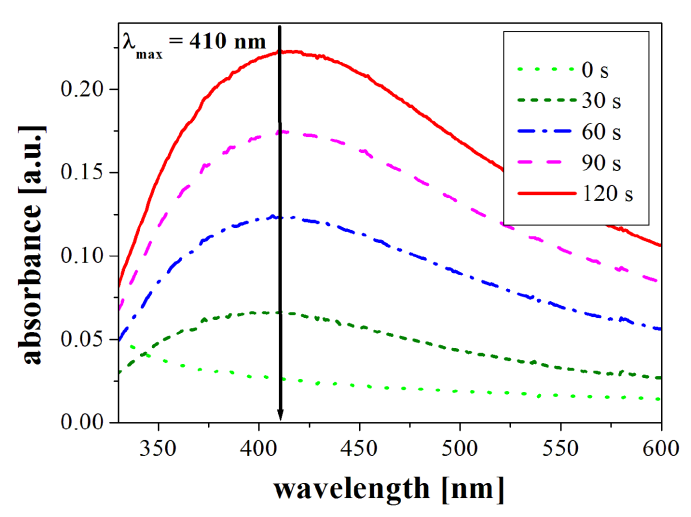

Figure 3. Absorption spectrum of $\mathrm{AgNO}_{3}$ solution $\left(100 \mathrm{mgl}^{-1}\right)$ during the dc discharge treatment $(100 \mathrm{~W})$ without the gas bubbling.

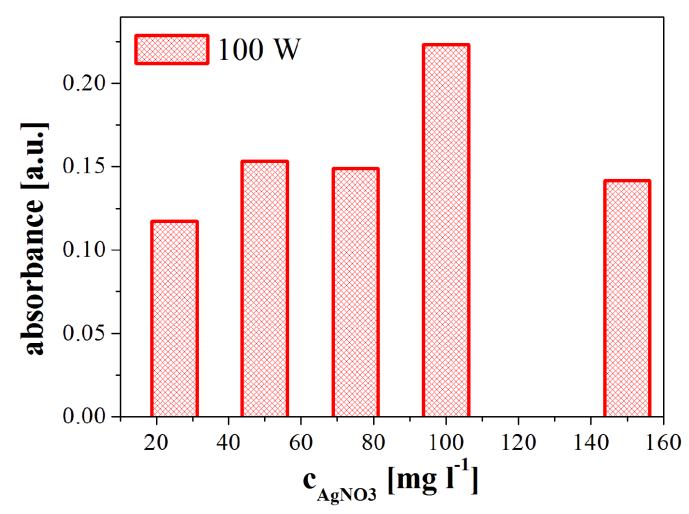

Figure 4. Comparison of NPs absorbance (at $410 \mathrm{~nm}$ ) after two minute discharge treatment $(100 \mathrm{~W})$ in $A g \mathrm{NO}_{3}$ solutions with different initial concentration and without the gas bubbling.

production of Ag NPs in presence of oxygen could be probably explained by higher variety of chemical reactions combining oxygen and water molecules which leads to the dissipation of energy to these mechanisms instead of the charge transfer needed for the silver reduction.

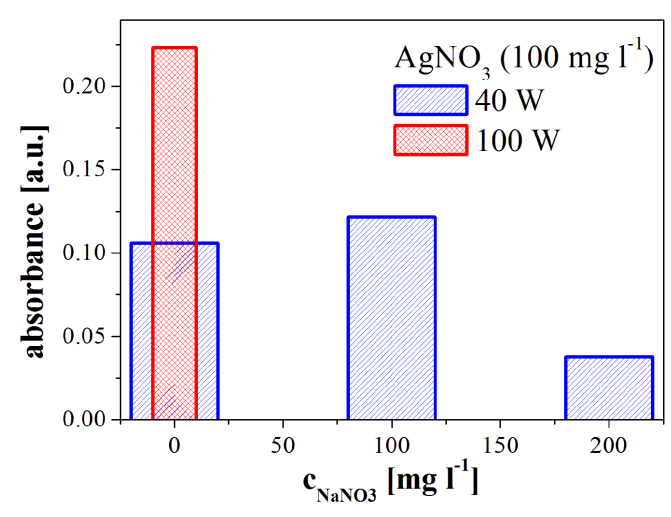

Figure 5. Comparison of NPs absorbance (at $410 \mathrm{~nm}$ ) after two minute discharge treatment ( 40 or $100 \mathrm{~W}$ ) in $\mathrm{AgNO}_{3}$ solutions (100 mg l-1) with different $\mathrm{NaNO}_{3}$ addition and without the gas bubbling.

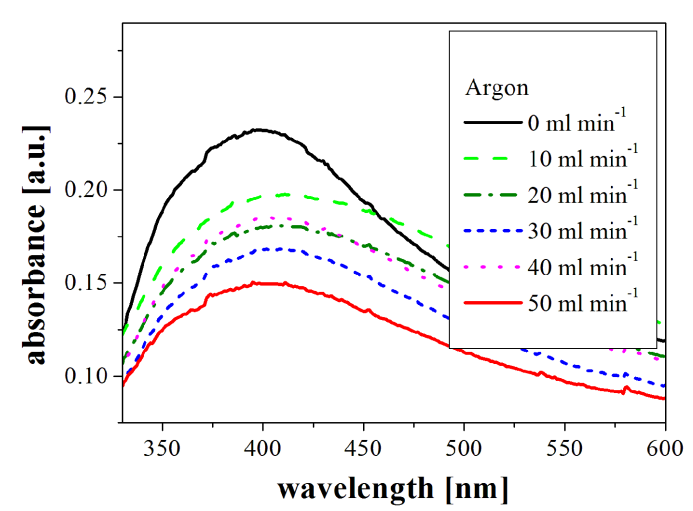

Figure 6. Absorption spectrum of $\mathrm{AgNO}_{3}$ solution $\left(100 \mathrm{mgl}^{-1}\right)$ after two minute discharge treatment $(100 \mathrm{~W})$ with different flow rate of argon.

\section{Conclusions}

Silver nanoparticles were produced using the pin-hole discharge generated by dc non-pulsing high voltage directly in water solutions containing silver nitrate as the nanoparticle precursor. Formation of silver 


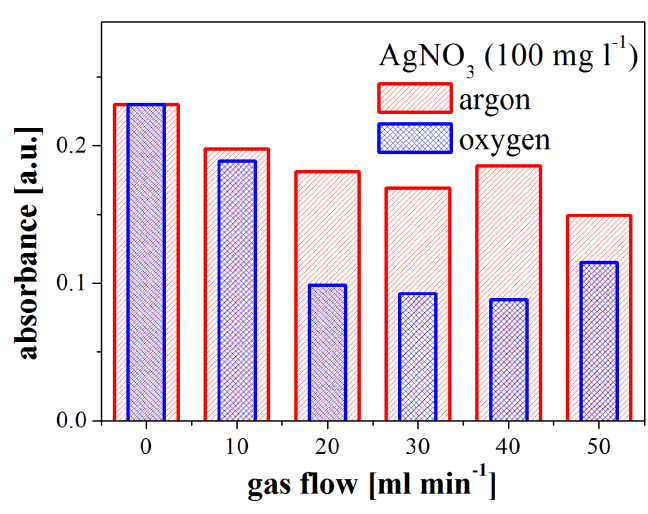

Figure 7. Comparison of NPs absorbance (at $410 \mathrm{~nm}$ ) after two minute discharge treatment $(100 \mathrm{~W})$ in $\mathrm{AgNO}_{3}$ solutions $\left(100 \mathrm{mgl}^{-1}\right)$ with different flow rate of argon and oxygen.

nanoparticles (mean size of $100 \mathrm{~nm}$ ) was confirmed by SEM/EDS analysis. Further, UV-VIS spectrometry (absorption maximum at $410 \mathrm{~nm}$ ) was involved for comparative experiments. Maximal production of $\mathrm{Ag}$ NPs was achieved at optimal $\mathrm{AgNO}_{3}$ concentration of $100 \mathrm{mg} \mathrm{l}^{-1}$ and applied power of $100 \mathrm{~W}$. Addition of sodium nitrate, which increased the initial solution conductivity as well as decreased the minimal applied power, negatively influenced the Ag NPs formation. Also additional gas bubbling through the discharge region has a negative effect on the nanoparticle formation, both for argon and oxygen. Especially in case of oxygen, dissipation of applied energy into variable chemical reactions instead of to the reduction process was assumed.

\section{References}

[1] M. Naito et al. Nanoparticle technology handbook. Second printing. Elsevier, 2012.

[2] Z. Abdullaeva. Synthesis of nanoparticles and nanomaterials: Biological approaches. Springer International Publishing, 2017.

[3] D. L. Fedlheim and C. Foss. Metal nanoparticles: Synthesis, characterization, and applications. CRC Press, 2001.

[4] G. Sharma et al. Revolution from monometallic to trimetallic nanoparticle composites, various synthesis methods and their applications: A review. Mat. Sci. Eng. C Mater., 71:1216-1230, 2017. doi:10.1016/j.msec.2016.11.002.

[5] A. Rahnama and M. Gharagozlou. Preparation and properties of semiconductor $\mathrm{CuO}$ nanoparticles via a simple precipitation method at different reaction temperatures. Opt. Quant. Electronics, 44:313-322, 2012. doi:10.1007/s11082-011-9540-1.

[6] W. Choi and J. Lee. Graphene: Synthesis and applications. CRC Press, 2011.
[7] P. R. Sharma et al. Spherical shaped nanoparticles of cellulose and its derivatives: A short review. Trends Carbohydrate Res., 7:1-5, 2015.

[8] B. Pejjai et al. Status review on earth-abundant and environmentally green $\mathrm{Sn}-\mathrm{X}(\mathrm{X}=\mathrm{Se}, \mathrm{S})$ nanoparticle synthesis by solution methods for photovoltaic applications. Int. J. Hydrogen Energy., 42:2790-2831, 2017.

[9] S. A. Paknejad and S. H. Mannan. Review of silver nanoparticle based die attach materials for high power/temperature applications. Microelectron. Reliab., 70:1-11, 2017. doi:10.1016/j.microrel.2017.01.010.

[10] E. Roy et al. Developing electrochemical sensor for point-of-care diagnostics of oxidative stress marker using imprinted bimetallic Fe/Pd nanoparticle. Talanta, 132:406-415, 2015.

doi: 10.1016/j.talanta.2014.09.033.

[11] E. V. Agina et al. Polymer surface engineering for efficient printing of highly conductive metal nanoparticle inks. ACS Appl. Mater. Inter., 7:11755-11764, 2015. doi:10.1021/am508905t.

[12] E. Nezbedová et al. Effect of particles size on mechanical properties of polypropylene particulate composites. Int. J. Structural Integrity, 7:690-699, 2016.

[13] M. Jouni et al. A representative and comprehensive review of the electrical and thermal properties of polymer composites with carbon nanotube and other nanoparticle fillers. Polym. Int., 66:1237-1251, 2017. doi:10.1002/pi.5378.

[14] H. Teisala et al. Review on liquid flame spray in paper converting: Multifunctional superhydrophobic nanoparticle coatings. Nord. Pulp Pap. Res. J., 29:747-759, 2014.

[15] N. K. Rajendran et al. A review on nanoparticle based treatment for wound healing. J. Drug Deliv. Sci. Tec., 44:421-430, 2018.

[16] D. Peukert et al. Metallic nanoparticle radiosensitisation of ion radiotherapy: A review. Phys. Medica, 47:121-128, 2018. doi:10.1016/j.ejmp. 2018.03.004.

[17] F. Krčma et al. Characterization of novel pin-hole based plasma source for generation of discharge in liquids supplied by DC non-pulsing voltage. Plasma Sources Sci. Technol., 27(6):065001, 2018. doi:10.1088/1361-6595/aac521.

[18] D. Paramelle et al. A rapid method to estimate the concentration of citrate capped silver nanoparticles from UV-visible light spectra. Analyst, 139(19):4855-4861, 2014.

[19] F. Krčma, Z. Stará, and J. Prochazková. Diaphragm discharge in liquids: Fundamentals and applications. $J$. Phys.: Conf. Ser., 207(1):012010, 2010. doi:10.1088/1742-6596/207/1/012010. 